\title{
Development and Validation of RP-HPLC Method for Simultaneous Estimation of Ramipril, Aspirin and Atorvastatin in Pharmaceutical Preparations
}

\author{
RAJESH SHARMA, SUNIL KHANNA, AND GANESH P. MISHRA
}
School of Pharmacy, Devi Ahilya Vishwavidyalaya, Takshshila Campus, Khandwa Road, Indore-452017, M.P., India
rbsm73@yahoo.co.in

Received 08 October 2011; Accepted 03 December 2011

\begin{abstract}
A simple, sensitive, accurate and rapid reverse phase high performance liquid chromatographic method is developed for the simultaneous estimation of ramipril, aspirin and atorvastatin in pharmaceutical preparations. Chromatography was performed on a $25 \mathrm{~cm} \times 4.6 \mathrm{~mm}$ i.d, $5 \mu \mathrm{m}$ particle, $\mathrm{C} 18$ column with Mixture of (A) acetonitrile methanol (65:35) and (B) $10 \mathrm{mM}$ sodium dihydrogen phosphate monohydrate $\left(\mathrm{NaH}_{2} \mathrm{PO}_{4} \cdot \mathrm{H}_{2} \mathrm{O}\right)$ buffer and mixture of A:B $(60: 40 \mathrm{v} / \mathrm{v})$ adjusted to $\mathrm{pH} 3.0$ with o-phosphoric acid $(5 \% \mathrm{v} / \mathrm{v})$

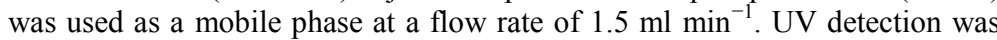
performed at $230 \mathrm{~nm}$. Total run time was less then $12 \mathrm{~min}$; retention time for Ramipril, aspirin and Atorvastatin were $3.620,4.920 \mathrm{~min}$ and $11.710 \mathrm{~min}$ respectively. The method was validated for accuracy, precision, linearity, specificity and sensitivity in accordance with ICH guidelines. Validation revealed that the method is specific, rapid, accurate, precise, reliable, and reproducible. Calibration plots were linear over the concentration ranges 05-50 $\mu \mathrm{g} \mathrm{mL}{ }^{-1}$ for Ramipril, $05-100 \mu \mathrm{gmL}^{-1}$ for aspirin and $02-20 \mu \mathrm{g} \mathrm{mL} L^{-1}$ for atorvastatin. Limits of detection were $0.014,0.10$ and $0.0095 \mathrm{ng} \mathrm{mL}^{-1}$ limits of quantification were $0.043,0.329$ and $0.029 \mathrm{ng} \mathrm{mL}^{-1}$ for ramipril aspirin and atorvastatin respectively. The high recovery and low coefficients of variation confirm the suitability of the method for simultaneous analysis of the all three drugs in the dosage forms. The validated method was successfully used for quantitative analysis of marketed pharmaceutical preparations.
\end{abstract}

Key Words: RP-HPLC, Simultaneous Estimation, Validation, Ramipril, Aspirin and Atorvastatin.

\section{Introduction}

Ramipril (RAM) is chemically: (1 S, 5S, 7S)-8-[(2S)-2- [[(IS)- 1 -ethoxycarbonyl-3-phenylpropvl]amino]propanovl]-8-azabicvclo[33O]octane-7- carboxylic acid ${ }^{1}$. It is an angiotensinconverting enzyme (ACE) inhibitor ${ }^{2}$. Ramipril is converted to ramiprilat by hepatic cleavage of the ester group, used to treat hypertension and congestive heart failure ${ }^{3}$. Aspirin is 2acetyloxybenzoic acid ${ }^{4}$, it is acetyl derivative of salicylic acid useful in the relief of 
headache and muscle and joint aches. aspirin is also effective in reducing fever, inflammation, and swelling and thus has been used for treatment of rheumatoid arthritis, rheumatic fever, and mild infection 3,4. Atorvastatin, is 7-[2-(4-fluorophenyl)-5-(1methylethyl)-3-phenyl-4-(phenylcarbamoyl)-1H-pyrrol-1-yl]-3,5-dihydroxy-heptanoic acid ${ }^{3,4}$.It is a selective, competitive HMG-CoA reductase inhibitor ${ }^{4}$, is used to lower cholesterol and triglycerides in patients with hypercholesterolemia and mixed dyslipidemia and in the treatment of homozygous familial hypercholesterolemia. This combination is used as lipid lowering and anti- hypertensive (ACE inhibitor) agents with analgesic, antipyretic effect. All the three drugs are official in Indian pharmacopoeia, British pharmacopoeia and extra pharmacopoeia ${ }^{1,5,6,7}$. Ramipril has been determined by UV-spectrophotometric ${ }^{8,9}$ and by HPLC methods ${ }^{10,11}$. Plasma determination of ramipril has also been reported ${ }^{12}$. The simultaneous determination of ramipril and atorvastatin was reported in the literature ${ }^{13}$. Various spectrophotometric ${ }^{14}$ and $\mathrm{HPLC}^{15-17}$ methods are reported for determination of aspirin and atorvastatin alone and in combination with other drugs. The objective of this study was to develop and validate specific, accurate, precise and reproducible quality control method for ramipril, aspirin and atorvastatin in their ternary combination.<smiles>[CH][C](N[C@H](C)C(=O)N1[C@H](C(=O)O)C[C@@H]2CCC[C@@H]21)C(=O)OC</smiles>

(a)<smiles>CC(=O)Oc1ccccc1C(=O)O</smiles>

(b)

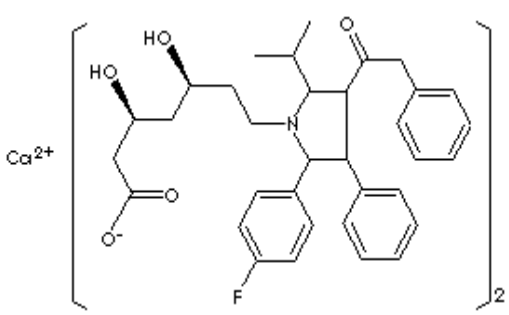

(c)

Figure 1. Chemical structures of Ramipril (a), Aspirin (b) and Atorvastatin calcium (c).

\section{Experimental}

\section{Chemicals and Reagents}

Pure samples of Ramipril, aspirin and atorvastatin were obtained as gift sample from Plethico Pharmaceuticals Pvt. Ltd., Indore, M.P., India and tested for purity. The solid dosage form (Polytorva Capsule) was procured from local market (Label claim: $5 \mathrm{mg}$ Ramipril, $75 \mathrm{mg}$ aspirin and $10 \mathrm{mg}$ atorvastatin). All the chemical and reagents used were of HPLC grade and purchased from Spectrochem, Mumbai, India. 


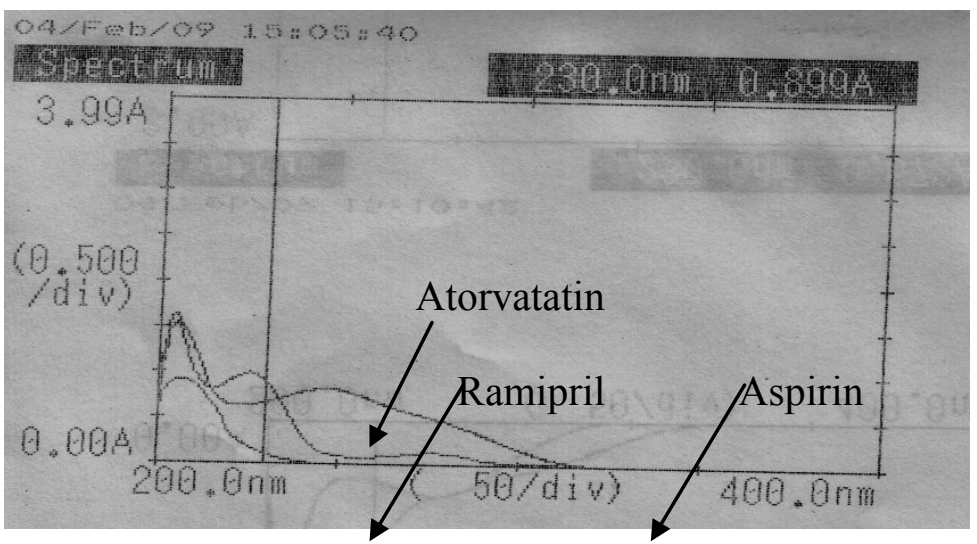

Figure 2. Overlain spectra of Ramipril, Aspirin and Atorvastatin.

\section{Equipment Used}

Shimadzu HPLC (LC-10 AT VP) system; LC system used consist of pump(Model SHIMADZU; LC- 10 AT VP) with universal loop injector(Rheodyne 7725 i) of injection capacity $20 \mu \mathrm{l}$. Detector consists of photodiode array detector SPD-10 AVP, SHIMADZU; the reverse phase column used was Luna $\mathrm{C}_{18}(5 \mu \mathrm{M}, 25 \mathrm{~cm} \times 4.6 \mathrm{~mm}$ i.d) phenomenex, USA, at ambient temperature.

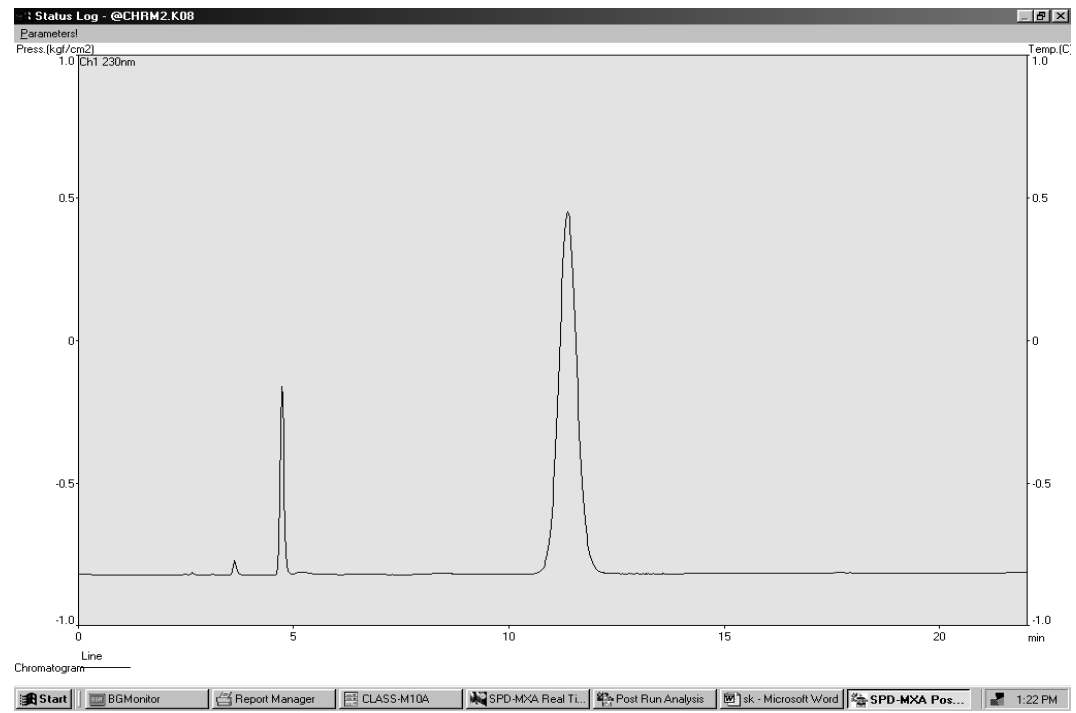

Figure 3. A typical chromatogram of Ramipril, Aspirin and Atorvastatin in marketed formulation.

\section{Preparation of Standard and Sample Solutions}

Ramipril, aspirin and atorvastatin (10 mg each) were weighed accurately and separately transferred to $100 \mathrm{~mL}$ volumetric flasks. Both drugs were dissolved in $25 \mathrm{~mL}$ methanol to prepare standard stock solutions. After the immediate dissolution, the volume was made up to the mark with mobile phase. These standard stock solutions were observed to contain 100 $\mu \mathrm{g} \mathrm{ml}^{-1}$ of Ramipril, aspirin and atorvastatin. 
Table 1. Results from assay of the marketed formulation.

\begin{tabular}{lcccccc}
\hline Drug & $\begin{array}{c}\text { Label claim } \\
(\mathrm{mg} \backslash \text { Capsule }) \\
\mathrm{n}=6\end{array}$ & $\begin{array}{c}\text { Amount } \\
\text { Found } \\
\text { in mg }\end{array}$ & $\begin{array}{c}\text { Drug } \\
\text { Concentration } \\
(\%)\end{array}$ & $\begin{array}{c}\text { COV } \\
(\%)\end{array}$ & SE \\
\hline Ramipril & 5 & 4.97 & 99.40 & 1.0 & 0.997 & 0.41 \\
Aspirin & 75 & 75.17 & 100.36 & 0.47 & 0.47 & 0.19 \\
Atorvastatin & 10 & 9.91 & 99.10 & 0.78 & 0.78 & 0.32 \\
\hline
\end{tabular}

S.D- standard deviation; $C O V$ - coefficient of variance; S.E- standard error; $n$ - Number of replicates.

For analysis of the dosage form, twenty Polytorva capsules were weighed individually and their average weight was determined. The capsules were empty out and then content crushed to a fine powder and powder equivalent to the weight of $5 \mathrm{mg}$ of ramipril (corresponding amount of aspirin $75 \mathrm{mg}$ and atorvastatin calcium $10 \mathrm{mg}$ ) was transferred to a $100 \mathrm{~mL}$ volumetric flask and dissolved in $25 \mathrm{~mL}$ methanol to prepare standard stock solutions. The solution was shaken vigorously for $15 \mathrm{~min}$ and filtered through Whatman \#41 filter paper, and the residue was washed with mobile phase. The solution was then diluted to $100 \mathrm{ml}$ with the solvent mobile phase.

Table 2. System suitability parameters.

\begin{tabular}{cccc}
\hline Property & Ramipril & Aspirin & Atorvastatin calcium \\
\hline $\boldsymbol{R}^{\boldsymbol{t}}$ & 3.620 & 4.920 & 11.710 \\
$\boldsymbol{T}_{\boldsymbol{f}}$ & 1.36 & 1.24 & 1.06 \\
$\boldsymbol{K}^{\boldsymbol{N}}$ & 0.00 & 0.30 & 2.14 \\
$\boldsymbol{N}$ & 6535 & 10353 & 3334 \\
$\boldsymbol{R}_{\boldsymbol{s}}$ & - & 6.05 & 13.65 \\
\hline
\end{tabular}

Rt, retention time; Tf, tailing factor; $k^{\prime}$, capacity factor; $N$, number of theoretical plates $R s$, resolution.

The mobile phase was a Mixture of (A) acetonitrile methanol (65:35) and (B) $10 \mathrm{mM}$ sodium dihydrogen phosphate monohydrate $\left(\mathrm{NaH}_{2} \mathrm{PO}_{4} \cdot \mathrm{H}_{2} \mathrm{O}\right)$ buffer and mixture of $\mathrm{A}: \mathrm{B}$ $(60: 40 \mathrm{v} / \mathrm{v})$ adjusted to $\mathrm{pH} 3.0$ with o-phosphoric acid $(5 \% \mathrm{v} / \mathrm{v})$ was used as a mobile phase at a flow rate of $1.5 \mathrm{ml} \mathrm{min}{ }^{-1}$, was used to sharpen the peak. The run time was less then 12 min. Before analysis, both mobile phase and sample solutions were degassed by sonication and filtered through $0.2-\mu \mathrm{m}$ filter paper. The analytes were monitored at $230 \mathrm{~nm}$. 
Table 3. Results of recovery studies.

\begin{tabular}{|c|c|c|c|c|c|}
\hline DRUG & $\begin{array}{c}\text { Amount taken } \\
\left.(\mu \mathrm{g} \mathrm{m} \mathrm{L})^{-1}\right)\end{array}$ & $\mathrm{L}^{-1}$ & $\mu \mathrm{g} \mathrm{m}$ & $\begin{array}{l}\text { Recovery } \\
(\%, \pm \text { S.D }) .\end{array}$ & $\begin{array}{l}\mathrm{COV} \\
(\%)\end{array}$ \\
\hline \multirow{3}{*}{ Ramipril } & \multirow{3}{*}{5} & 80 & 04 & 99.83 & 0.805 \\
\hline & & 100 & 05 & 100.87 & 0.413 \\
\hline & & 120 & 06 & 100.44 & 0.848 \\
\hline \multirow{3}{*}{ Aspirin } & \multirow{3}{*}{75} & 80 & 60 & 100.34 & 0.614 \\
\hline & & 100 & 75 & 100.10 & 0.384 \\
\hline & & 120 & 90 & 100.13 & 0.160 \\
\hline \multirow{3}{*}{ Atorvastatin } & \multirow{3}{*}{10} & 80 & 08 & 99.83 & 0.699 \\
\hline & & 100 & 10 & 99.33 & 0.459 \\
\hline & & 120 & 12 & 99.50 & 0.718 \\
\hline
\end{tabular}

S.D., standard deviation; $C O V$, coefficient of variance.

\section{Construction of Calibration curves}

From the standard stock solutions of all the three drugs, different dilutions were prepared and chromatographed and the peak areas were measured. Calibration plot of concentration against peak area were then constructed for ramipril, aspirin and atorvastatin. From the calibration plots it was found that response to ramipril, aspirin and atorvastatin calcium was a linear function of concentration in the range $05-50,05-100 \mu \mathrm{g} \mathrm{mL}^{-1}$ and $02-20 \mu \mathrm{g} \mathrm{mL}^{-1}$ respectively. Unknown assay samples were quantified by reference to these calibration plots. The overlain spectra of the formulation are reported in Figure 2.

\section{Analysis of pharmaceutical Formulation}

Before assay of the formulations six replicates of the required dilutions were prepared from the stock solution and sonicated for $10 \mathrm{~min}$. The solutions $(20 \mu \mathrm{L})$ were then injected for quantitative analysis. The amounts of ramipril, aspirin and atorvastatin per capsules were calculated by extrapolating the peak area from the calibration curve. The results are reported in Table 1.

Under the optimum chromatographic conditions, the retention times obtained for ramipril, aspirin and atorvastatin calcium were $3.620,4.920 \mathrm{~min}$ and 11.710 respectively. Resolution $(R \mathrm{~s})$ between ramipril and aspirin was 6.05 and aspirin and atorvastatin was 13.65. Capacity factors, tailing factors, and number of theoretical plates are reported in Table 2.

\section{Recovery studies}

To perform the accuracy of the developed method and to study the interference of formulation additives, analytical recovery experiments were carried out by standard addition method. The results of the analysis are reported in Table 3. 
Table 4. Results from determination of intra-day and inter-day precision, and LOD and LOQ.

\begin{tabular}{|c|c|c|c|c|c|c|}
\hline \multirow{3}{*}{ Drug } & \multicolumn{6}{|c|}{ Inter-day precision $(\mathrm{COV}, \%)$} \\
\hline & \multirow{2}{*}{$\begin{array}{c}\text { Intra-day precision } \\
(\mathrm{COV}, \%)\end{array}$} & & & & \multirow{2}{*}{$\begin{array}{c}\text { LOD } \\
\text { ng mL }{ }^{-1}\end{array}$} & \multirow{2}{*}{$\begin{array}{c}\text { LOQ } \\
\text { ng mL }{ }^{-1}\end{array}$} \\
\hline & & Day 1 & Day 2 & Day 3 & & \\
\hline Ramipril & 1.499 & 1.428 & 1.655 & 1.651 & 0.014 & 0.043 \\
\hline Aspirin & 0.869 & 0.625 & 0.898 & 0.725 & 0.108 & 0.329 \\
\hline Atorvastatin & 1.213 & 1.195 & 1.148 & 1.192 & 0.009 & 0.029 \\
\hline
\end{tabular}

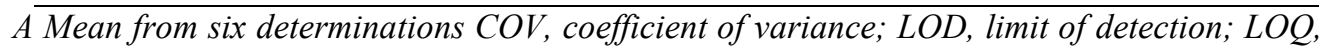
limit of quantitation.

\section{Validation}

The method was validated for linearity, accuracy, precision, repeatability, selectivity and specificity. Accuracy was studied by measurement of recovery at three different levels 80 , 100 , and $120 \%$ of the amount expected in the formulation, in accordance with ICH guidelines ${ }^{18,19}$. Precision was measured both intra-day and inter-day. In the intra-day study the concentrations of all three drugs were calculated three times on the same day at intervals of an hour. In the inter-day study the concentrations of all the three drugs were measured on three different days. The selectivity and specificity of the method were validated by injecting solutions containing all the three drugs; three sharp peaks were obtained for all the three drugs. The limits of detection and quantitation of the method were studied to detect the lowest amount of analyte and quantitative determination of analyte in a sample respectively. The results are reported in Table 4.

\section{Results and Discussion}

All the three components of the dosage form were identified by comparison of retention times obtained from sample and standard solutions. The work was performed in an airconditioned room maintained at $25 \pm 2{ }^{\circ} \mathrm{C}$. Column chemistry, solvent type, solvent strength (volume fraction of organic solvent(s) in the mobile phase and $\mathrm{pH}$ of the buffer solution), detection wavelength and flow rate were varied to determine the chromatographic conditions giving the best separation. The mobile phase conditions were optimized so that the capsules components were free from interference from the solvent and from excipients. Other criteria, for example time required for analysis, appropriate $k$ range for eluted peaks, assay sensitivity, solvent noise, and use of the same solvent system for extraction of the drug from formulation matrices during drug analysis were also considered. After trying columns containing different stationary phases, the final choice giving satisfactory resolution and run time was the $25 \mathrm{~cm} \times 4.6 \mathrm{~mm}$ i.d, $5-\mu \mathrm{m}$ particle; Phenomenex Luna $\mathrm{C} 18$ reversed-phase column. A series of aqueous mobile phases containing phosphate buffer solutions of different $\mathrm{pH}$ in combination with different volume fractions of acetonitrile as modifier were also tested. The best results were obtained by use of Mixture of (A) acetonitrile methanol (65:35) and (B) $10 \mathrm{mM}$ sodium dihydrogen phosphate monohydrate $\left(\mathrm{NaH}_{2} \mathrm{PO}_{4} \cdot \mathrm{H}_{2} \mathrm{O}\right)$ buffer and mixture of $\mathrm{A}: \mathrm{B}(60: 40 \mathrm{v} / \mathrm{v})$ adjusted to $\mathrm{pH} 3.0$ with o-phosphoric acid $(5 \% \mathrm{v} / \mathrm{v})$ is used to sharpen the peak. The flow rate was determined by testing the effect of different flow rates on peak area and resolution; $1.5 \mathrm{~mL} \mathrm{~min}^{-1}$ was found to be optimum. All experiments 
were performed at ambient temperature. The values obtained for $k$ and $R \mathrm{~S}(1<k<10, R \mathrm{~S}>$ 2 ) show these chromatographic conditions are appropriate for separation and quantification of both the compounds. The number of plates $(N)$ is a measure of column efficiency; which shows the high separation efficiency of the column used.

\section{Conclusions}

A new, reversed-phase HPLC method has been developed for simultaneous analysis of ramipril, aspirin and atorvastatin in a solid formulation. It was shown above that the method was accurate, reproducible, repeatable, linear, precise, and selective, proving the reliability of the method. The run time is relatively short, i.e. $12 \mathrm{~min}$, which enables rapid quantitation of many samples in routine and quality control analysis of formulations. The optimized solvent system was used throughout the experimental work and no interference from any excipient was observed. These results have shown that method could find practical application as a quality-control tool for simultaneous analysis of all three drugs from their combined dosage forms in quality-control laboratories.

\section{Acknowledgment}

The authors are grateful to Plethico Pharmaceuticals Pvt. Ltd Indore, M.P., India for providing gift samples and also thankful Mr. Suresh Prajapati for providing assistance during work.

\section{References}

1. Indian Pharmacopoeia, Vol. III, New Delhi. The controller of publication Govt. of India $164,2007$.

2. Goodman and Gilman, the Pharmacological basis of therapeutics, 10th edition, New York, McGraw Hill Book, 1701, 2001.

3. Martindale, The Complete Drug Reference; Pharmaceutical Press: London, 33rd edition. 966, 2003 .

4. The Merck index, An encyclopedia of chemicals, drugs and biological, 13th Merck Research

5. Laboratories, Division of Whitehouse Station, NJ Merck and Co Inc, 140, 2001.

6. British Pharmacopoeia, The stationary office London Vol 1, 1479, 2002.

7. United States Pharmacopoeia-29 / National Formulary-24, United States Pharmacopoeial Convention, Inc; Rockville, MD, 1280, 2006.

8. European Pharmacopoeia, Vol II 5th edn, Council of Europe, Strasbourg codex, France, 2355, 2002.

9. Vachareau A and Neirinck L, Indian Drugs, 37, 2000, 589-593.

10. Megda M, Ayad A, Shalaby E, Abdellate F, J PharmBiomed Anal., 28, 2002, 311-317.

11. Mohite P B, Pandhare R B, Bhaskar V H, Eurasian J Anal Chem,5, 2010,89-94.

12. Zarapkar S S and Rane S H, Indian Drugs, 37, 2000, 589-593.

13. Stanisz B and Kania L, Acta. Pol. Pharm., 63, 2006, 471-476.

14. Joseph L, Mathew G and Venkata R, Pak. J. Pharm. Sci., 21, 2008,282-284.

15. Mishra P. and Archana D, Indian J Pharm Sci., 68, 2006, 365-368. 
16. Anandakumar K, Ayyappan T, Raghu Raman V, Vetrichelvan T, Sankar A, Nagavalli D. Indian J Pharm Sci., 69, 2007, 597-599.

17. S Erturk S, Sevinc A E, Ersoy L and Ficicioglu S, J Pharm Biomed Anal., 33, 2003, 1017-1023.

18. Yadav S S, Thaske D V, Kakad A B, Patil B D, Kadam S S, Dhaneshar S R., Indian J Pharm Sci, 67, 2005,182-187.

19. Sharma R, Mishra G P, Chaturvedi S C, E-J Chem., 3,7, 2010, 947-952.

20. ICH guidelines on Validation of Analytical Procedures, Text and Methodology Q2 (R1)," FDA, Published in the Federal Register 60, 1995. 


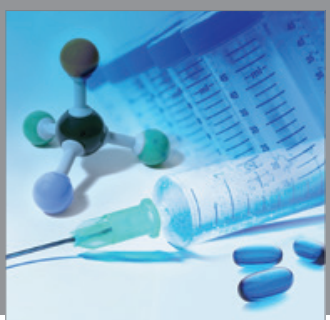

International Journal of

Medicinal Chemistry

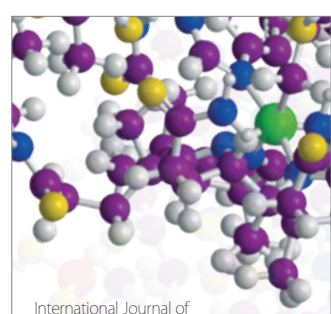

Carbohydrate Chemistry

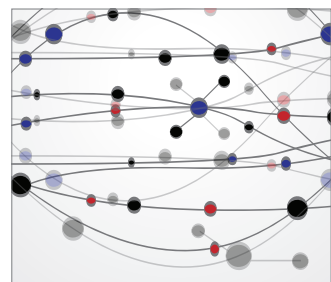

The Scientific World Journal
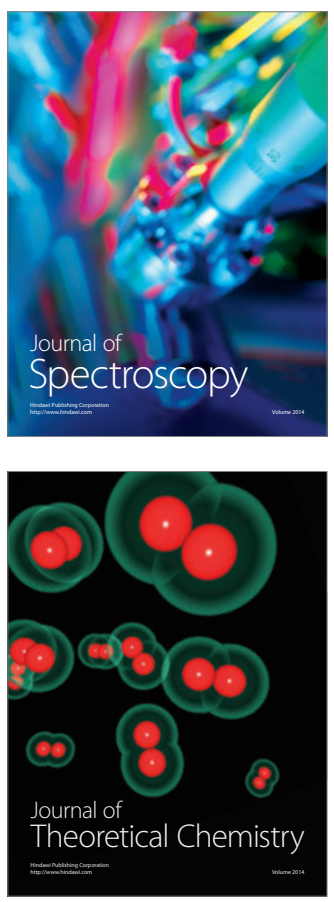
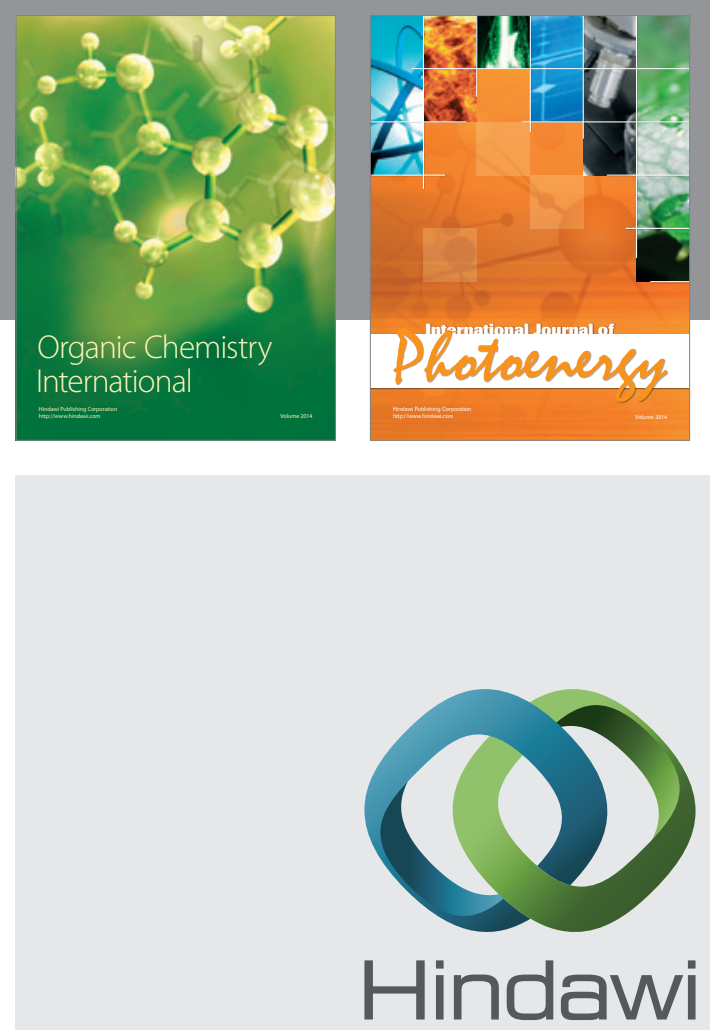

Submit your manuscripts at

http://www.hindawi.com
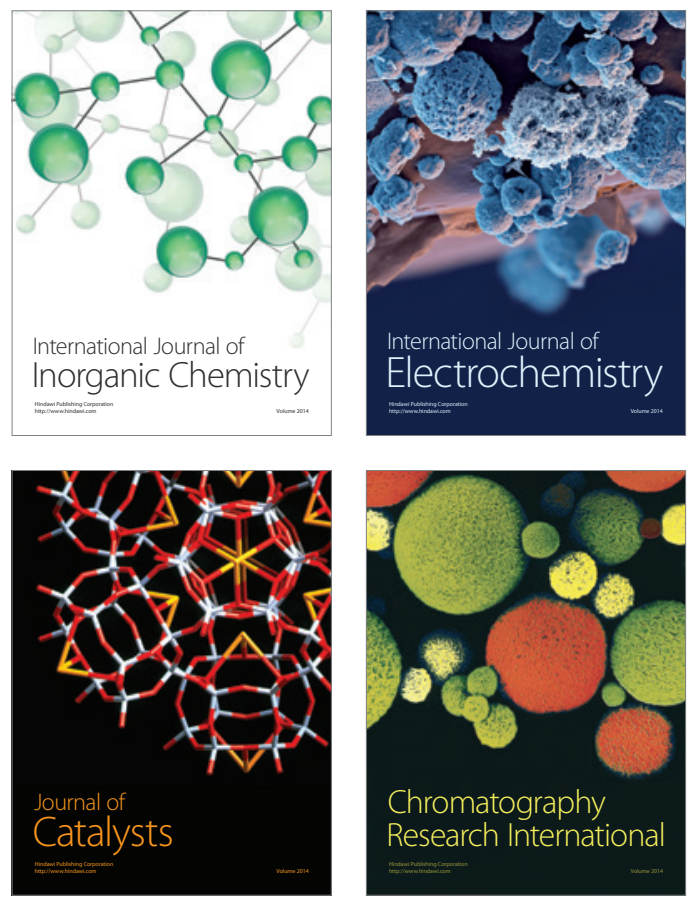
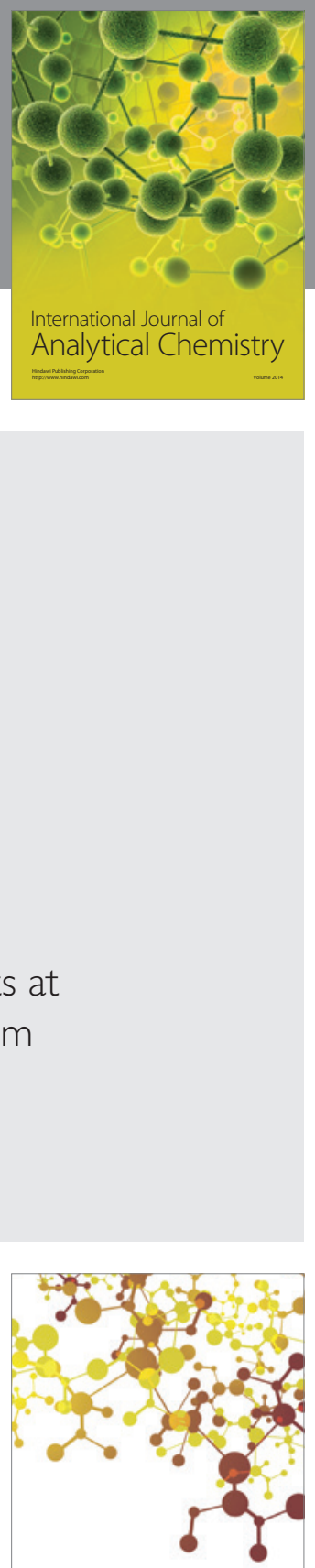

Journal of

Applied Chemistry
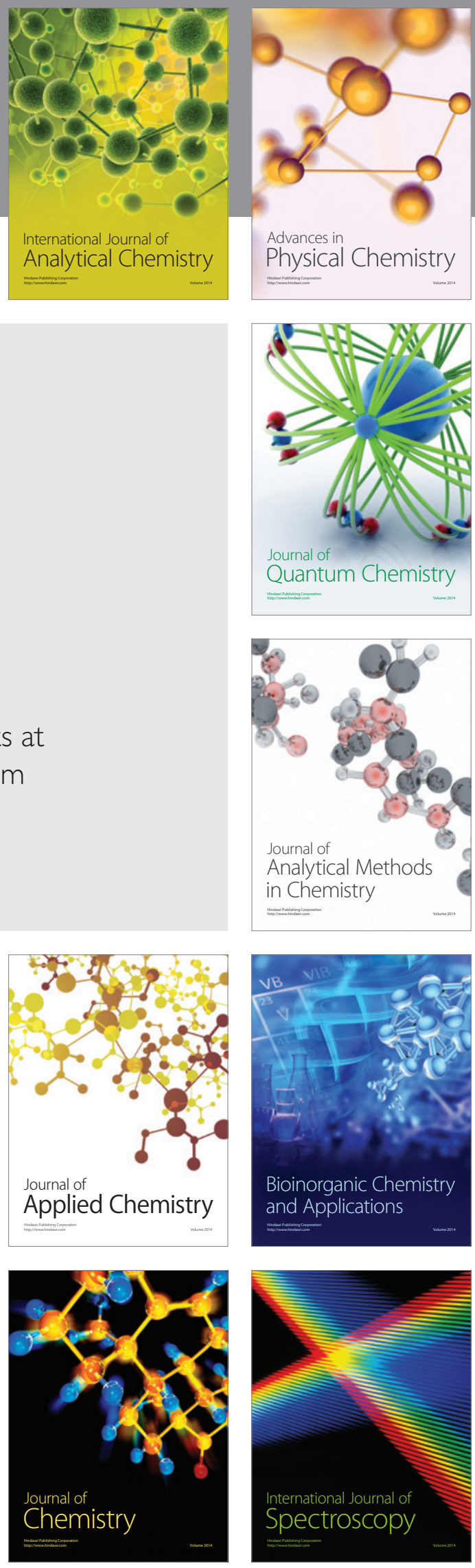